\title{
Stakeholder involvement in the management of effluent discharges from nuclear installations in France
}

\author{
T. Schneider' ${ }^{1}$ S. Gadbois ${ }^{2}$, G. Hériard Dubreuil ${ }^{2}$, A. Sugier ${ }^{3}$, A. Oudiz ${ }^{3}$ \\ and L. Vaillant ${ }^{1}$ \\ ${ }^{1}$ CEPN, BP. 48, 92263 Fontenay-aux-Roses Cedex, France, e-mail: schneider@cepn.asso.fr \\ ${ }^{2}$ MUTADIS, Paris, France \\ ${ }^{3} I R S N$, Fontenay-aux-Roses, France
}

\begin{abstract}
The involvement of local stakeholders in the decision-making process regarding health, safety and environmental issues is developing in many countries. As far as the management of effluent discharges from nuclear installations in France is concerned, members of Local Commission of Information, including elected people and NGOs, are playing an increasing role in that respect. To deepen the understanding of these risk governance processes, a working group of experts from different institutions was set up in 2000 by the Institute of Radiation Protection and Nuclear Safety (IRSN). Several case studies concerning the involvement of stakeholders were performed, among them: the dialogue process around the discharges of the COGEMA La Hague reprocessing plant, the role of the local liaison committees of the Fessenheim and Gravelines nuclear power plants. Four main elements, contributing to the social trust, emerge from this analysis: 1) the social dynamics of the consultation process, notably with the emergence of "new" stakeholders such as elected people and NGOs; 2) the readability of the plant follow-up from the point of view of local stakeholders and their involvement in the decision process (the relay role of these "new" stakeholders); 3) the contribution of the institutional and pluralist expertise to the social trust (broadening of the range of values taken into account); 4) the issue of the local justification of the plant in the prospect of the sustainable development (no risk being acceptable without counter-parts). This paper addresses these different issues on the basis of the case studies in the perspective of examining the radiological risk governance process.
\end{abstract}

\section{INTRODUCTION}

Recent experiences in Europe and elsewhere have demonstrated that new approaches taking into account the specific context of the risk situations and based on the concrete involvement of relevant stakeholders within new democratic procedures may help to re-establish a constructive dialogue between scientists, experts, politicians and the civil society, and to facilitate the elaboration of efficient, sustainable and accepted decisions. These new experiences fall within the general trend in Europe towards a new governance and citizenship (see presentation of two European projects in Annex). To deepen the understanding of these risk governance processes, a pluri-disciplinary group, chaired by Annie Sugier, and involving IRSN personnel and other experts in the field of risk governance, radiation protection, and environmental law, was set up in 2000 by IRSN to develop a reflection on the efficacy and practicability of such new governance processes for nuclear installations. For this purpose, detailed analyses of processes were performed, with a specific emphasis on the role of the local liaison committees around nuclear installations. This paper presents three case studies (concerning COGEMA La Hague installation, Fessenheim and Gravelines nuclear power plants) and provides the main conclusions of this working group. 


\section{CASE STUDIES}

\subsection{The dialogue process around the discharges of the COGEMA-La Hague facility in France}

In 1981, the Deputy of Cherbourg created a commission devoted to providing information on the installation of COGEMA La Hague, composed of local elected people, local NGOs, experts from public organisations and national NGOs and representatives from the workers of the COGEMA reprocessing plant. This commission is called: "Commission Spéciale Permanente d'Information près de l'Etablissement de La Hague" (CSPI).

\section{The GRNC experience}

In 1995 and 1997, Professor Viel published the results of epidemiological studies analyzing the evolution of leukaemia incidence among the youth of Beaumont-La Hague district and questioning the link between this and COGEMA reprocessing plant discharges. Due to the vivid controversy raised by these publications, the national authorities set up a Scientific Commission chaired by professor Souleau to make a new epidemiological study. The Commission released its interim report, and two new experts were charged to continue the work: Annie Sugier, Director of Radiation Protection in IRSN and Pr. Alfred Spira, Research Director in INSERM. The mission of the "Groupe Radioécologie Nord-Cotentin" (GRNC) chaired by Annie Sugier was to estimate the risk of leukemia for young people in the 0-24 years age group near the La Hague site (in the Beaumont-Hague canton), starting from the evaluation of exposure received as a result of the different radiation sources (natural, medical diagnosis and industrial nuclear installations in the Nord-Cotentin). Professor Spira was in charge of looking further into the epidemiological studies. The GRNC, composed of experts with various origins (experts from authorities, organisations specialising in this field and operators as well as experts from a number of local and national NGOs and European organisations), significantly contributed to dialogue on COGEMA La Hague facilities in Nord-Cotentin. Setting up a forum enabled the different groups of experts involved firstly to assess their mutual credibility, which is a prerequisite for debate. Thus, a consensus was gradually established about the quality of measurements made by the various participants. The existence of a structure including experts from different social backgrounds allowed the group to deal with points of disagreement or even controversy, without the use of invective. This provides a setting for a common search for solutions. The evaluation modelling also benefited greatly from the inclusion of local people, notably regarding the integration of local habits and practices.

\section{The revision process of the regulatory authorisations}

In parallel, a dialogue had been engaged since 1994 between COGEMA and the nuclear safety authority to modify the decrees of authorization associated with the initial creation of the site and to review the authorizations of discharges. Following the application by COGEMA requesting modifications of its authorizations of creation (DAC), the nuclear safety authority ordered in September 1998 an ad hoc pluralist group of experts to give its views on the admissibility of the safety and impact studies provided by the operator. The Group was chaired by Annie Sugier, as President of GRNC. Views were requested from IRSN in parallel. During this period, discussions continued within the administration as regards the scope of COGEMA request: should it be limited to the modification of the authorization decree for the initial creation of the site or should it cover the modification of the discharge authorizations? The first analysis of the operator application files, both by the pluralist group of experts and by IRSN, ended up with a negative advice as regards the file suitability and a request for further information. Following the complements brought by COGEMA, the nuclear safety authority again seized the group of experts which gave a favourable opinion at the beginning of 1999, while making explicit criticisms in particular on the impact study of chemical releases and on the justification of the maximum level of expected radiological discharges. The public 
inquiry started on February 2000 the $2^{\text {nd }}$ and ran until May 17, 2000. At the request of the Ministry of the Environment the report of the group of experts was made available with the application file submitted to public comment. The last step to the new discharge authorizations. The nuclear safety authority requested an advice from IRSN in May 2000 "on the technical basis to determine the limits as regards the radioactive component of discharges". In its answer, in September 2000, the IRSN presented "an analysis of the operation range required by COGEMA with the current processes and examined ways of improvement on the short-term or longer-term, likely to reduce further the levels of radioactive releases". IRSN played its role of expert, proposing alternatives, while the final decision still belonged to the authorities. In parallel, the GRNC continued its own work. In particular, in July 2000, it was entrusted with a new mission on: 1 . the analysis of uncertainties associated with the impact assessment of radiological releases, 2. the impact study of chemical releases.

\section{Some lessons from the case study}

This case study shows the difficulty faced by the actors who are not involved in the relation between the technical operator and the administration, and more particularly for the local actors, to have a comprehensive view on the authorization process as far as nuclear facilities are concerned. It also highlights important steps forward in dialogue. The study underlines the development of an informal dialogue between the administration and the operator before the official application and much before the public inquiry. This situation damages the readability and understanding of the process and blurs the distinction between the roles of the operator and the administration. The trustworthiness of the whole process is thus questioned. As for the public inquiry, it remains a tool mainly devoted to meet administration's concerns in the decision-making process. So far it doesn't clarify the reasons for the final decision, as the technical arguments are partly not made public. Thus, the questions made by the public during the inquiry are usually not responded to, and there is no place for a dialogue with the operator. Questions are transmitted to the inquiry Inspector once the consultation is closed. In the same way, the limits set in the decree of discharge authorization (January 10, 2003) were not debated or commented. One must underline however that this decree plans a revision of authorization within 4 year as well as an annual assessment of the dose impact by the GRNC. As regards dialogue, the analysis of this case study stresses various innovative features. By widening the scope of the admissibility examination to a pluralist group of experts, the authorities opened the field of expertise. Moreover, the pluralist group of experts broadly built on the work of GRNC. Taking into account its level of expertise and its knowledge of the impact of COGEMA La Hague plant releases, this group of experts was able to thoroughly analyze the safety and impact study and to ask the operator for relevant details. The comments made by the group of experts were largely taken into account by the administration and also taken over by NGOs in their own comments.

\subsection{Fessenheim NNP local liaison committee}

The Local Monitoring Commission of Fessenheim is the first Local Committee created in France next to a nuclear site. The Commission was set up in 1977 following a vivid debate about nuclear projects in the Rhine plain. The authorisation was contested in front of the State Council, and was opposed with a hunger strike. A second Local Commission was created in 1979 near another nuclear power plant (NPP) in France. A regulatory framework was given in 1981 by the Mauroy circular "to facilitate the creation of local commissions around all large energy equipments", nuclear power plants in the first place, with initiative from the General Councils (Département). One of the principal challenge for the Fessenheim Commission was to find its place in the oversight of the NPP, when follow up activities were still primarily carried out through a well established relation of control between the operator and the administration. In relation to EDF, the Commission had difficulties to escape a role of mere relay of information. With respect to the administration, it encountered difficulties to reach documents and to express an autonomous point of view on decisions taken by the 
local state bodies. This led in 1983 to the boycott of the Local Commission by the General Councillors. In 1989, when the first decennial visit of the NPP started, the Local Commission financed two counter-evaluations, one on the reactor safety with GSIEN ${ }^{1}$, the other on radioecology with CRII$\mathrm{RAD}^{2}$. This monitoring role by way of autonomous expertise was explicitly translated in the new statutes of the commission in 1994: "the purpose of the Commission is to facilitate, especially for the population of Haut-Rhin, the access to information on the operation of Fessenheim NPP. The Commission can order expertise concerning particular points relative to this operation. (...) The Local Monitoring Commission with the support of the majority of its members can request the General Council to resort to expertise on particular matters presented either by the NPP operator, the DSIN ${ }^{3}$, the DRIRE ${ }^{4}$ or any other organization".

Several factors were determining in the capacity of the Commission to develop this monitoring role. The Commission comprises a limited number of members, which facilitates work in sub-commission, follow-up activities, as well as the analysis of the experts' reports. The Commission has a full-time secretariat and uses the services of the Environment department of the General Council. The Commission has a specific line for its operation in the General Council budget. That includes about 15000 Euros per year for expertise (usually doubled with the same amount by the DRIRE, the local state administration for industry, research and environment). EDF, permanent guest in the Commission, takes an active part in the work of the Commission by its collaboration, in particular by providing an access to documents and answering questions. Contrary to the guidelines proposed by the Mauroy circular, the General Council did not wish the Commission to be cofinanced by the operator. Expertises made by GSIEN and CRII-RAD are framed by a convention signed by the Local Commission, the independent experts, the DRIRE and the operator. The General Council of the Haut-Rhin and the local DRIRE financially support those expertises. A pluralist steering committee with an administrative representative of the Local Commission, a local councillor, an association and a representative of the DRIRE follows the work done by the experts. The second decennial visit made it possible to measure the evolution of the situation of the NPP, but even more to normalize and prioritize the questions raised, and to identify the relevant actors to address each one of them. This work was also an opportunity to identify points of consensus and debate. For the Commission, this was an important moment to specify its monitoring mandate in the duration, and to make more explicit its role of local oversight and mediation. Nevertheless, a debate on the scope and nature of this role still continues, mainly between NGOs and elected representatives.

\subsection{Gravelines NPP local liaison committee ${ }^{5}$}

At the beginning of the 1970ies, the decision to build an oil power plant in the area of Dunkirk (North France) was taken in order to provide electricity to the many industries established in this area. The site of Gravelines was selected, but with the oil crisis, the plans were reviewed and it was decided to build a Nuclear Power Plant. Within a spread climate of contesting against nuclear energy, it led to an important opposition move. Nevertheless, the building of a NPP in Gravelines started in 1974 and ended in 1980. The reactors started operating between 1980 and 1985. Considering the persisting conflicting climate, the mayor of Gravelines initiated the creation of a Local Commission for Information (CLI) in order to show that nuclear industry had nothing to hide and was not less safe than other kinds of industry. The General Council of the Department officially created the CLI in 1987 in order to meet the needs expressed by the citizens for clear, accurate and complete information on the site. Its members were nominated by a Departmental decree. The CLI, which has no legal statutes, is funded by local

\footnotetext{
${ }^{1}$ Groupe de Scientifiques pour l'Information sur l’Energie Nucléaire.

${ }^{2}$ Commission de Recherche et d'Informations Indépendantes sur la RADioactivité.

${ }^{3}$ Direction de la Sûreté des Installations Nucléaires (Nuclear Safety Authority).

${ }^{4}$ Direction Régionale de l'Industrie, de la Recherche et de l’Environnement.

${ }^{5}$ It should be mentioned that this case study is not issued from the report of the IRSN working group but from the RISKGOV project.
} 
communities (mainly Gravelines, Dunkirk and the Department) and the DRIRE. The commission gathers more than one hundred of official members (local elected people, public authority representatives, local NGOs, Trade Union representatives, operator and medical authority representatives) but only 20 people regularly take part to its activities. In order to improve the quality of its work, the CLI created two sub-commissions in 1996: a "technical" sub-commission in charge of the technical aspects of the plant functioning and a "population safety" sub-commission whose activities deal with the protection of the population and the management of nuclear accident situation. Two or three plenary sessions are organized each year. The technical sub-commission meets 3 or 4 times a year to debate on new projects, incidents or discharges into the environment. Generally speaking, members of the CLI appear to be in a vigilant position, taking care of the surveillance of the nuclear power plant at the local level. Their role is rather to analyse regularly the data and information available within the Commission. They have also the possibility to ask for complementary measurements or explanations concerning key issues of safety management. To improve the quality of their work, members of the CLI can beneficiate of several sources of expertise at local or national level.

At the same time, they play the role of relay of the local population interrogations, they question the operator and they transfer the information to the local population. The CLI publishes regularly (3 times per year) a news bulletin and sends it to inhabitants living close to the power plant (100,000 copies). Most of the members of the CLI are also involved in different local and regional organisations or risk governance processes dealing with the protection of the environment and/or the industrial development (notably the Permanent Secretariat for Protection of Industrial Pollution). They wish they were associated with the organisation of the vigilance in the region as far as environment and industry is concerned, while keeping at the same time a specific risk governance process for the NPP in order to avoid a larger forum that would not be able to tackle the specific questions raised by the surveillance of the NPP, such as the question of the ageing of the nuclear power plants in France. In fact, the CLI appears to be a favourable place for local NGOs to have an accurate view of the exchanges between the authority (DRIRE) and the operator (EDF) in their involvement in the management of the safety of the nuclear power plant. Therefore, thanks to the autonomy given to the participants of the Commission to seek for information and to express their own points of view, it is possible for them to have an influence on the way potential events are anticipated and managed. Furthermore, the CLI which gathers people representing the local population (mayors) and environmental interests (NGOs) seems to occupy a strategic place in the communication with the public about the risk management of the NPP. Despite of this privileged positioning of the CLI, the interviewed participants underlined the fundamental problem of the absence of a legal statute for the Commission. In consequence, people see limits in the access and diffusion of information and feel the need to clarify the roles of the members within the CLI as well as the official role of the CLI within the risk management process around the nuclear power plant of Gravelines. The case of the CLI of Gravelines shows that people involved in the risk management around the NPP of Gravelines managed to create the conditions of a dialogue between a plurality of representatives of the civil society. Several aspects of the governance process such has the autonomy given to NGOs to express their questionings, the possible requirement to different sources of expertise or the perception of frank exchanges between the authority and the operator have clearly contributed to build confidence on a long term between the participants.

\section{MAIN CONCLUSIONS OF THE WORKING GROUP}

The reflections initiated by the working group set up by IRSN started with the view that "new" actors are involved in the management of effluent discharges from nuclear facilities in France. Hence there is a need to better understand who these "new" actors are, what their contribution in the decision making process consists in and to what extent this participation challenges the existing process. 


\subsection{The social dynamics of dialogue}

Since several years, an evolution can be observed on the regulation processes related to industrial activities. The traditional delegation mechanisms involving administration, operators and public experts are confronted with difficulties characterized by:

- a perception that operators, experts and regulators could have shared interests,

- a decrease in the perceived quality of safety, and a loss of confidence in safety systems,

- blocked decision-making processes, and the expectation that decision-making process should be more accountable to local stakeholders.

Public confidence in these mechanisms tends to be put into question and progressively local actors play an increasing role in the decision-making processes. These actors may be non expert people, such as local elected representatives and members of various NGOs, as well as "independent" experts (i.e. not belonging to the official expert appraisal institutes). Such an evolution, which is clearly observed within the framework of the authorization processes related to effluent discharges of industrial plants, can be observed also as far as safety matters are concerned. Local commissions are set to implement the dialogue between the administration, operators and public experts and the local actors. Generally, administration, operators and public experts reached with time an agreement on a technical common approach to safety or radiation protection questions. However, the rationale of this common approach is far from being perceived as shared with the local population. Involving local actors in the decision making processes allows them to bring in other considerations, due notably to more specific local concerns. Local NGOs and some independent experts, as well as local elected people, play an innovative relay role between the local population and the administration, operators and public experts.

\subsection{A need for a better "readability" of the decision-making process}

The involvement of local actors in a continuous process of follow-up of the industrial plants allows a better understanding of the technical problems and a progressive elaboration of a common language with the other involved actors. A long-term dialogue contributes also to mutual understanding between the actors, which is a prerequisite for social trust. The involvement of local actors certainly contributes to the transparency of the decision making processes but it goes beyond: these actors are well aware of local aspects of the operation of the plants and bring out relevant safety or radiation protection questions which deserve appropriate answers.

\subsection{The contribution of pluralistic expertise to the quality of the decision making processes}

The management of effluent discharges is no longer a matter for sole experts from the operator and the public authorities. There is an increasing interest from local actors - members of NGOs, elected people or mere citizens - to get insight in the process and to give their views. From the local actors' point of view, safety or radiation protection expertise brought out by the operators or the authorities appears very hard to understand. The involvement of « independent » experts may contribute to bring contradictory assessments and enhance a better understanding of technical issues by the non experts. Such an involvement increases the overall credibility of the decision making processes by opening them to experts generally perceived locally as sharing the same values as the local actors. Existence of an independent expertise capacity may appear insufficient if conclusions cannot be drawn by the local actors from the contradictory expertise process, due to difficulties to understand the technical stakes. It may be important that local actors have a technical support to help them to point out the key issues and conclusions. 


\subsection{The local justification of hazardous activities taking into account sustainable development}

The above reflections relate primarily to issues of risk assessment and risk management. However, the continuity of operation for a facility in a given territory and public confidence are based not only on the tolerability of the risks associated with its activity but also on the justification of its existence in the eyes of the local actors. The justification of a facility cannot be based only on global considerations. It must rest on a positive contribution to the local actors' quality of life, on the sustainable development of the local territory as well as on the protection of its quality and value. In this prospect, the dialogue and the relations between a facility and the local actors could not be limited to the dimension of the risk. Indeed, the existence of a risk exposure or an impact on the territory can hardly find a justification in itself. From this point of view, one sees that new forms of dialogue are made necessary in order to go beyond safety considerations - which remain a too narrow field to build a genuine common stake between the involved actors (local actors and operators).

\section{CONCLUSION}

In order to share these analyses and to favour an exchange of experiences between different categories of actors, two seminars were organised by IRSN at Ville d'Avray in 2003 and 2004. Various delegates from the administration, expert agencies, NGOs, elected people, trade-unions and industry were invited and discussed experiences of dialogue in the vicinity of nuclear and non-nuclear facilities. Several questions were raised throughout the seminars on the purpose of dialogue. Through discussions, participants made an attempt to better define the objectives of dialogue, its conditions and limits. Is it a way to manage conflicts of interest and to try to reach common views? Does it substantially improve the oversight of a facility? The participants reinforced the importance of taking account of the economic stakes as far as the dialogue processes and the radiation protection strategies cannot ignore them. As a whole, dialogue remains a difficult process, which requires mediation skills, a mid term or even long term prospect, dedicated resources and an ethical framework. These various elements are often incomplete, but they are all essential to move from stakeholder involvement intellectual concepts to practical dialogue.

\section{ANNEXE: European projects on risk governance}

During the last few years, two European projects have made a significant contribution to the elaboration of recommendations regarding risk governance: TRUSTNET and RISKGOV.

TRUSTNET is a European network established in 1997, focussed on developing, refining and influencing governance arrangements and practice for hazardous activities and their impact on public health and the environment. TRUSTNET identified the severe difficulties and multiple social blockages affecting the credibility, effectiveness and legitimacy of traditional regulatory framework of hazardous activities. It has identified emerging features of inclusive risk governance as a major opportunity for overcoming the observed difficulties. Currently, the TRUSTNET-IN-ACTION project aims at creating the conditions for a group of stakeholders involved in some innovative processes to work out a common inclusive risk governance culture.

The RISKGOV Project was developed within the 5th European Framework Programme between 2001 and 2004. It aimed at analysing and identifying quality criteria for the governance of industrial activities giving rise to risks to people and the environment from radioactive and chemical discharges during normal operations. Among the criteria under-review, one can notice: the multi-level governance aspects, the role of expertise in the decision-making process, the influence of the stakeholders involvement on the improvement of this process, the consideration of the various scopes of the decision making process (risk, sustainable development, quality of the environment...) and the decision implementation in itself. 


\section{References}

[1] Hériard Dubreuil G, Gadbois S., Concertation autour des sites industriels, Mutadis, Rapport IRSN, Avril 2001.

[2] Schneider T., Hériard Dubreuil G, Gadbois S., Oudiz A., Rémond Gouilloud M., Concertation autour des sites industriels, rapport du Groupe de Travail, 16 décembre 2002.

[3] Actes du Séminaire de Ville d'Avray du 21 et 22 janvier 2003 sur la concertation autour des sites d'installations industrielles, IRSN, Décembre 2003.

[4] Sugier A., Hériard Dubreuil G., Gadbois S., Schneider T., Oudiz A., Concertation autour des sites industriels, Note de synthèse d'une démarche de réflexion de l'IRSN, Décembre 2003.

[5] Schneider T., et al., RISKGOV: Comparative Analysis of Risk Governance for Radiological and Chemical Discharges of Industrial Installations. In: International Congress of the International Radiation Protection Association, IRPA11, Madrid, Spain, 23-28 May 2004.

[6] Hériard Dubreuil G., Towards an Inclusive Governance of Hazardous Activities: Conclusions from the 2000-2003 TRUSTNET Activities. In: OECD Nuclear Energy Agency Third Villigen Workshop, Paul Scherrer Institute, Switzerland, 21-23 October 2003. 